\title{
Knowledge and attitudes of nursing students towards evidence-based medicine and evidence-based nursing practice
}

\begin{abstract}
Introduction. Modern nursing practice requires Nursing students to expand their knowledge both in the field of specialized nursing and learning the basics of medicine, as based on scientific evidence. The dissemination of research activities in nursing and the development of the profession, knowledge and practice based on Evidence-based Nursing may contribute to the increase of the effectiveness and improving the quality of healthcare services. Nursing teaching curricula should include subjects related to Evidence-based Medicine, such as scientific research methodology or critical analysis of scientific literature.

Aim. The aim of the study was to analyze the knowledge and attitudes of nursing students towards Evidence-based Medicine (EBM) and Evidence-based Nursing Practice (EBNP).

Material and methods. Out of 127 Master's degree students in Nursing at the Medical University of Warsaw (4 men), $72 \%$ work as a nurse. Mean age of the study group was 26.55 years (min. 22, max. 51, SD=7.52) with $63 \%$ of the students attending full-time studies, with $90 \%$ being students of the first year. Some 53\% earned their bachelor's degree in Nursing in 2013. A standardized Evidence - Based Practice Profile Questionnaire from University of South Australia, quantitative analysis of the study results.

Results. Nearly $30 \%$ of the respondents have never encountered EBM or EBNP during their time at the University ( $\mathrm{n}=41$ ). Most students intend to use relevant scientific literature in order to update their knowledge ( $\mathrm{n}=68$ ) and to upgrade their skills, so as to integrate EBNP into their everyday professional practice $(n=67)$. Some $60 \%$ of the respondents deem scientific reports useful for their work $(n=76)$ but nearly half of them regards clinical experience as more important than the results of scientific studies, when it comes to making the right decisions in their professional practice $(n=56)$. Nearly a half of the studied group $(\mathrm{n}=66)$ have never heard about the term minimum clinically worthwhile effect and only one person declared the correct explanation systematic review $(\mathrm{n}=1) .42 \%$ declare reading published scientific studies once a month but nearly $30 \%$ have never referred scientific findings to their own diagnosis $(n=41)$ and $40 \%$ have never assessed its methodological correctness $(n=51)$.

Conclusions. 1. The educational programs in the framework of Nursing studies should be supplemented with subjects of EBM and EBNP, so as to expand the nursing students' knowledge and let them reap the benefits of using the latest study results in their future professional practice. 2. The level of knowledge about the principles of assessment of reliability of scientific evidence was strongly insufficient and requires urgent supplementation of knowledge and skills of students in this area. 3 . It is necessary for students to update their knowledge, particularly when it comes to using the latest scientific literature in everyday clinical practice and skills connected with critical analysis of scientific evidence.
\end{abstract}

Keywords: evidence-based medicine, evidence-based nursing practice, safety, nursing care quality.

DOI: $10.1515 / \mathrm{pjph}-2015-0055$

\section{INTRODUCTION}

Modern nursing practice requires Nursing students to expand their knowledge in various fields. This pertains not only to specialist nursing but also learning the basics of evidencebased medicine. Health care workers, including nurses or midwives should be able to make use of and apply the most recent research findings in their professional practice, in order to ensure safe and effective patient care that meets the highest quality standards. The use of scientific evidence in clinical practice can be beneficial not only for the safety of an individual patient or the medical staff but it can also boost the financial effectiveness and efficiency of medical procedures performed [1-11].
The ability to make correct decisions in nursing practice means reaching the right clinical diagnosis but on the basis of one's knowledge about the scientific data and ability to determine whether it is credible enough. Hence, the ever-growing emphasis on the use of scientific research finding in the professional practice of midwives which is expected to have a positive impact on patients' and medical staff safety, as well as the medical procedures effectiveness or financial efficiency. The main task, then, is to raise Nursing students' awareness about using the latest scientific research findings, as well as the necessity to upgrade their skills and competences in conducting scientific research [1-11]. 
The Education Nursing students in the course of first- and second-level studies at higher education medical institutions with long-term experience in conducting scientific research and implementing their results in clinical practice should place an even greater emphasis on education in the field of conducting scientific research, analysis of research findings or ability to critically read scientific texts, that is all the key elements of Evidence-based Practice and Evidence-based Medicine.

The dissemination of research activities in nursing and the development of the profession, knowledge and practice based on evidence-based Nursing may contribute to the increase of the effectiveness and quality of provided health services. It is of huge importance to include subjects related to Evidencebased Medicine, such as the scientific research methodology and critical analysis of the scientific literature, in the Nursing studies curriculum.

\section{AIM}

The aim of the study was to analyze the Nursing students' knowledge and attitudes toward evidence-based practice, as well as investigating how often do they use research findings in their professional activities.

\section{MATERIAL AND METHODS}

The study looked at 127 students of level II studies of Nursing (4 male) at the Medical University of Warsaw (MUW). The mean age of the study group members was 26.55 years (the youngest person was 22 , the oldest $-51, \mathrm{SD}=7.52$ ). 91 members of the study group work in the profession. 80 of those studied were full-time students of full time studies, whilst for some 114 of them, it was the first post-graduate course ever. The age analysis indicates that people working as nurses took up second-level studies at a much later period. Some 42 members of the study group earned their Bachelor's degree at a university other than MUW. Also, some 42 people from the whole group studied claimed they had never come across Evidence - Based Practice. Table 1 provides detailed information about the study group, along with an analysis of numerousness and age of respondents is given in Table 1.

TABLE 1. Characteristics of the studied groups of students of Nursing.

\begin{tabular}{|c|c|c|c|c|c|}
\hline & $\mathrm{n}$ & $\mathrm{p}^{*}$ & Mean Age & SD & $\mathrm{p}^{* *}$ \\
\hline $\begin{array}{l}\text { People working } \\
\text { in the nursing profession }\end{array}$ & $\mathrm{n}=91$ & \multirow{2}{*}{$>0.05$} & 23.8 & \pm 2.80 & \multirow{2}{*}{$<0.05$} \\
\hline $\begin{array}{l}\text { People not working } \\
\text { in the nursing profession }\end{array}$ & $\mathrm{n}=36$ & & 28.9 & \pm 8.74 & \\
\hline
\end{tabular}

$\mathrm{p}^{*}$ - nonparametric $\mathrm{Chi}^{2}$ compliance test (for $\mathrm{p}>0.05$ no significant difference between number of people in the groups)

$\mathrm{p}^{* *}$ - nonparametric U Mann-Whitney Test to compare the significance of age differences in the two study groups of students (for $\mathrm{p}<0.05$ both groups are significantly different)

The authors used the diagnostic probe method. The research was conducted between March and April 2014 and it was conducted online (in order to see it, follow the link: https://docs. google.com/forms/d/1oC0rcwPJFWLvzg74rP1rZOf3UvtpE_ yuQzhR845Uk8/viewform?usp=send_form). It was the questionnaire 'Evidence-Based Practice Profile Questionnaire' developed by a team of authors: McEvoy, Williams, Olds of the School of Health Sciences, University of South Australia, Adelaide [12]. The authors of the present study obtained the consent for its use. The questionnaire was validated and it was translated twice - each time by two different translators for the use in our own research.

The study was voluntary and used an anonymous questionnaire that included 4 questions using the Likert scale or the nominal scale in the area of professional practice based on scientific evidence. There were 13 questions concerning personal information, education and employment, as well as one question about the participant's knowledge about the subject matter of the study (namely, whether they had ever had encountered it before.) The questions concerning evidence-based practice were divided into 7 subject domains:

1. Nursing students' knowledge of and attitudes toward EBP

2. Students' attitudes to expanding their EBP competence

3. Applying EBP to professional nursing practice

4. Knowledge of EBP terminology

5. How often were individual EBP elements applied in everyday nursing practice

6. Individual levels of EBP-related skills

7. Advantages and barriers of applying EBP by nursing students.

The data was entered into a Microsoft Excel Sheet 2010 (v14.0). It was then analyzed using the STATISTICA (version 10.0) software, using the license issued by the Medical University of Warsaw.

The analysis of the questionnaire results was conducted using nonparametric tests for independent groups: U Mann-Whitney test for Likert scale questions (domains 1, 3, 6 and 7) or Pearson $\mathrm{Chi}^{2}$ test for questions with the nominal scale (domains 2,3 and 5). The value of $\alpha$-Cronbach coefficient was used to determine the reliability of the questions based on Likert-scale. It was used to evaluate the internal compliance of measurement results.

$\mathrm{P}<0.05$ was accepted as the statistical significance level for all analyses.

\section{RESULTS}

In the evaluation of the degree of reliability of the questions based on the Likert scale (domains 1, 3, 6 and 7; a total of 44 questions) the total level of the internal compliance of the measurement findings was high and amounted to $\alpha=0.849$. A detailed analysis of reliability showed that in the case of Domain 3 the questions fell into two separate groups which cross-measured the same set of features and properties of the respondent. That is why this domain was divided into two sub-domains $3 \mathrm{a}$ and $3 \mathrm{~b}$. The results of the reliability analysis for questions based on the Likert scale is given in Table 2.

TABLE 2. Results of the reliability analysis for individual domains of the questionnaire based on the Likert scale.

\begin{tabular}{|c|c|}
\hline Subject scope of the domain & $\alpha$-Cronbach Coefficient \\
\hline $\begin{array}{l}\text { 1: Nursing students' knowledge of } \\
\text { and their attitudes toward EBP }\end{array}$ & 0.91 \\
\hline 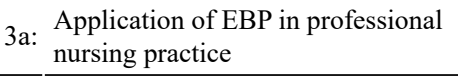 & 0.84 \\
\hline $\begin{array}{l}\text { 3b: Application of EBP in professional } \\
\text { nursing practice }\end{array}$ & 0.79 \\
\hline 6: Level of EBP-related skills & 0.90 \\
\hline $\begin{array}{l}\text { 7: Advantages and contradictions } \\
\text { for using EBP by nursing students }\end{array}$ & 0.76 \\
\hline
\end{tabular}


The aim of the Domain 1 was to measure the students' awareness about the existence, significance and development of EBP in the field of health sciences. Some $36 \%$ of the students declared that they are aware of EBP in their profession (Table 3).

TABLE 3. The answers of nursing students about the awareness of EBP in nursing profession.

\begin{tabular}{lc}
\hline \multicolumn{1}{c}{ I am aware of EBP in my profession } & Nursing students (n) \\
\hline Not at all true & 28 \\
\hline Not really true & 17 \\
\hline Possibly true & 20 \\
\hline Quite likely true & 46 \\
\hline Very true & 11 \\
\hline
\end{tabular}

In Domain 2, students expressed their opinions about expanding their knowledge about EBP. Some $38 \%$ of the future nurses have declared they are eager to upgrade their skills related to EBP. Only 5 students showed no interest in it at all (Table 4).

TABLE 4. Students' answers about attitudes to developing the skills related to EBP.

\begin{tabular}{ll}
\hline $\begin{array}{c}\text { I intend to master my skills of accessing, } \\
\text { acquiring and appraising evidence relevant } \\
\text { to my area of practice }\end{array}$ & Nursing students (n) \\
\hline No intention at all & 5 \\
\hline Unlikely to consider doing it & 17 \\
\hline I might consider doing it & 48 \\
\hline It is likely that I'd consider doing it & 40 \\
\hline Absolutely intend doing it / keep doing it & 17 \\
\hline
\end{tabular}

The objective of Domain 3 was checking students' knowledge about applying EBP in the professional nursing practice. Nursing students reported a huge awareness about the individual elements of EBP in their professional practice (Table 5).

TABLE 5. Students' answers about their relation to improving individual skills connected with EBP.

\begin{tabular}{ll}
\hline \hline $\begin{array}{l}\text { I am interested in learning or improving the skills } \\
\text { essential for integrating EBP into my work }\end{array}$ & Nursing students (n) \\
\hline Strongly disagree & 5 \\
\hline Disagree & 8 \\
\hline Neutral & 15 \\
\hline Agree & 85 \\
\hline Strongly agree & 12
\end{tabular}

In Domain 4, students were asked to evaluate their knowledge of EBP terms. In the question concerning the understanding of the term 'forest plot' a significant number of respondents declared that they had never heard about it. Only 2 students were reported to have good knowledge and partial understanding of this term (Table 6).

TABLE 6. Answers of the study group concerning the term 'forest plot'.

\begin{tabular}{ll}
\hline \multicolumn{1}{c}{ Forest plot } & Nursing students (n) \\
\hline Never heard the term & 68 \\
\hline Have heard it but I don't understand & 29 \\
\hline Have some idea & 18 \\
\hline Understand quite well & 8 \\
\hline Understand and could explain to others & 2 \\
\hline
\end{tabular}

The subject of the Domain 5 was 'How frequent were the individual EBP elements in everyday nursing practice'. In reply to the question 'How often in the past year have critically appraised any literature you have discovered to determine the methodological quality?' the formulation of such questions once a month or more rarely was declared by 41 students. $40 \%$ declare that they have never did it (Table 7).

TABLE 7. Frequency of the application by respondents of EBP elements in everyday professional practice.

\begin{tabular}{|c|c|}
\hline $\begin{array}{l}\text { Critically appraised any literature you have } \\
\text { discovered to determine the methodological } \\
\text { quality? }\end{array}$ & Nursing students (n) \\
\hline Never & 51 \\
\hline Monthly or less & 41 \\
\hline Fortnightly & 17 \\
\hline Weekly & 14 \\
\hline Daily & 1 \\
\hline
\end{tabular}

The aim of Domain 6 was to assess the students' confidence of engaging in activities related to EBP. Some $36 \%$ declared they are quite confident in applying information to individual cases in their professional practice (Table 8).

TABLE 8. Students' answers about the activities related to EBP.

\begin{tabular}{lc}
\hline $\begin{array}{c}\text { Ability to apply information to individual cases } \\
\text { (integrate research evidence with personal } \\
\text { preferences, values, concerns, expectations) }\end{array}$ & Nursing students (n) \\
\hline Not at all confident & 18 \\
\hline A little confident & 9 \\
\hline Reasonably confident & 46 \\
\hline Quite confident & 46 \\
\hline Very confident & 7 \\
\hline
\end{tabular}

The last Domain 7 was focused on predispositions and barriers limiting the application of EBP by nursing students. For almost a half of the studied group insufficient time is the main barrier to implement EBP into everyday practice (Table 9).

TABLE 9. Students' answers about the constraints limiting the application of EBP.

\begin{tabular}{lc}
\hline $\begin{array}{l}\text { Insufficient time is one of the greatest barriers } \\
\text { to the use of EBP in my clinical/professional } \\
\text { practice }\end{array}$ & Nursing students (n) \\
\hline Strongly disagree & 10 \\
\hline Disagree & 7 \\
\hline Neutral & 35 \\
\hline Agree & 60 \\
\hline Strongly agree & 15 \\
\hline
\end{tabular}

\section{DISCUSSION}

The authors used scientific online databases, such as PubMed, SCOPUS, EMBASE or PROQUEST. The search criteria were as follows: dates of search between 1 January 2000-12 November 2013, language of publication: English; (keywords: nursing, evidence-based practice, evidence-based nursing practice) we found numerous publications dealing with opinions and attitudes of different groups of nurses on evidencebased nursing practice [1-11]. 
Most publications focused on everyday clinical practice or primary health care, instead of educating Nursing students about EBP [5-11,13]. Notwithstanding that, all authors point to the necessity of including the EBP issues in the learning programs as early as possible [5-11,13].

Students of medical universities all over the world have the opportunity of benefiting from different forms of education which are directly related with EBP [11]. Various Polish curricula of nursing studies include the elements of evidencebased nursing practice, for instance in subjects like Scientific Research in Nursing.

In the US, the subject evidence-based nursing interventions was dealt with by Aronson and included in the curriculum of the $1^{\text {st }}$ semester of Nursing studies as early as 2003 . This had a marked impact on both the education quality and students' satisfaction with what they had to learn. It also helped them prepare better for clinical classes in the following semesters [7]. In 2011, authors from Iran noticed similar patterns in their study looking at 41 Medicine and Nursing students. This study confirmed the effectiveness of including the EBNP paradigm as the basis of teaching students and that it should constitute grounds for clinical education [8].

The findings above comply with what Florin and coworkers found out [10]. In 2006, they researched a group of 1440 students at 26 different universities (this figure constituted some $68 \%$ of the nursing students' population) in Sweden. Their study reveals that the emphasis on the importance of developing EBP-related skills in the course of pre-clinical education was markedly more extensive than in the course of clinical education, directly with a patient. Students were clearly better prepared for the application of published scientific research findings within theoretical education at university than within practical education. Moreover, students declared they were well-prepared to apply EBP at work $(\approx 8.1$, on a 10 -grade scale) [10]. The research findings obtained by Florin and co-workers do not comply with our own findings. Only 53 Nursing students declared adequate abilities to apply scientific information to their research work, inability to determine the degree of the clinical usefulness of scientific evidence gained $(n=46)$ or inability to determine the degree of its reliability $(n=63)$.

Similar results were obtained by Morris and co-workers [11] who conducted a study on a group of students of different health sciences in the course of second-level studies who took part in EBP classes in the course of first-level studies. Morris analyzed students' self-assessment with regards to their clinical competence. The study confirmed that students' participation in EBP classes boosts their opinion about their own skills and confidence, especially regarding their preparation for clinical classes and performing work-related tasks. It is worth emphasizing that factors responsible, in students' opinion, for the limitation of the application of EBP assumptions in work with a patient include lack of time and organization culture which make it impossible for nurses to fully apply the latest scientific research findings in everyday clinical practice. Our own research indicates as the principal factor limiting the application of research findings lack of time by nursing students for personal scientific development and search for new, reliable research findings $(n=65)$ along with the professional work load $(n=54)$. Students participating in the study admit that the application of EBP in professional practice helps them take the right clinical decisions concerning patients $(n=48)$ and contributes to the improvement of medical services rendered by them.
The dynamic development and improving competences made it necessary for the medical staff, including nurses, to permanently upgrade their professional skills and expertise, as well as find new information already during their time at the university. Expansion of these students' knowledge of methodology of scientific research, critical analysis of its results or their ability to critically read scientific texts, that is all the key elements of Evidence-Based Practice, can have a significant impact not only on the development of competences of students and specialists in this field but also on the future development of the whole nursing as a science.

\section{CONCLUSIONS}

1. The educational programs in the framework of Nursing studies should be supplemented by the subjects of EBM and EBNP in order to expand the nursing students' knowledge towards the benefits of using the latest study results in their future professional practice.

2. The level of knowledge about the principles of assessment of reliability of scientific evidence was strongly insufficient and requires urgent supplementation of knowledge and skills of students in this area.

3. It is necessary to expand students' knowledge with reference to use the latest scientific literature in everyday clinical practice and skills connected with critical analysis of scientific evidence.

\section{REFERENCES}

1. Williams AB. Praktyka pielęgniarska oparta na faktach. Sztuka Pielęgnowania. 2013;4:14-5.

2. Gajewski P, Jaeschke R, Brożek J. Podstawy EBM czyli medycyny opartej na danych naukowych dla lekarzy i studentów medycyny. Kraków: Medycyna Praktyczna; 2008.

3. Kędra E. Praktyka pielęgniarska oparta na faktach - wymóg czy konieczność? Probl Pielęg. 2011;19(3):391-5.

4. Kózka M. Zastosowanie badań naukowych w praktyce pielęgniarskiej. Pielęg Epidemiol. 2007;2/3:13-5.

5. Adams S. Barron S. Use of evidence-based practice in school nursing: Prevalence, associated variables, and perceived needs. Worldviews on Evidence-Based Nurs. 2009;6:16-26.

6. Martin F. Why we do what we do: Implementation of practice guidelines by family nurse practitioner students. JAANP. 2008;10:515-21.

7. Aronson BS, Rebeschi LM, Westrick-Killion S. Enhancing Evidence Bases for Interventions in a Baccalaureate Program. Nurs Educ Perspect. 2007;5:57-62.

8. Jalali-Nia SF, Salsali M, Dehghan-Nayeri N, Ebadi A. Effect of evidencebased education on Iranian nursing students' knowledge and attitude. Nurs Health Sci. 2011;13(2):221-7.

9. Logan PA, Angel L. Nursing as a scientific undertaking and the intersection with science in undergraduate studies: implications for nursing management. J Nurs Manag. 2011;9(3):407-17.

10. Florin JA, Ehrenberg AB, Wallin LA, Gustavsson PC. Educational support for research utilization and capability beliefs regarding evidencebased practice skills: A national survey of senior nursing students. JAN. 2012;68(4):888-97.

11. Morris JA, Maynard VB. The value of an evidence based practice module to skill development. Nurs Educ Today. 2007;27(6):534-41.

12. McEvoy MP, Williams MT, Olds TS. Evidence based practice profiles: Differences among allied health professions. BMC Med Educ. 2010;10:69 doi:10.1186/1472-6920-10-69.

13. Gijbels H, O’Connell R, Dalton-O'Connor C. A systematic review evaluating the impact of postregistration nursing and midwifery education on practice. Nurs Educ in Practice. 2010;10(2):64-9.

\section{Corresponding author}

Jarosława Belowska

81 Żwirki i Wigury Str., 02-091 Warszawa,

tel./fax: (22) 5720 490, (22) 5720491

E-mail: jaroslawa.belowska@wum.edu.pl 